isoform in active patients, suggest a stronger value of this isoform as a biomarker of disease activity.

References:

[1] Cohen RA, Bayliss G, Crispín JC et al. T cells and in situ cryoglobulin deposition in the pathogenesis of lupus nephritis. Clin Immunol 2008;128:1-7.

[2] Seiter S, Schadendorf D, Tilgen et al. CD44 variant isoform expression in a variety of skin-associated autoimmune diseases. Clin Immunol Immunopathol 1998;89:79-93.

[3] Crispín JC, Keenan BT, Finnell MD et al. Expression of CD44 variant isoforms CD44v3 and CD44v6 is increased on T cells from patients with systemic lupus erythematosus and is correlated with disease activity. Arthritis Rheum 2010;62:1431-7.

Disclosure of Interest: None declared

DOI: 10.1136/annrheumdis-2017-eular.3671

\section{THU0679 CAN THE USE OF NEW TECHNOLOGIES IMPROVE THE USE OF PATIENT REPORTED OUTCOMES (PROS) AND PATIENT PARTICIPATION IN A NATIONAL REGISTRY?}

L. Cunha-Miranda ${ }^{1}$, H. Santos ${ }^{1}$, F. Barcelos ${ }^{1}$, N. Madeira ${ }^{1}$, S. Fernandes ${ }^{1}$ J. Borges $^{1}$, R. Marques ${ }^{1}$, C. Silva ${ }^{1}$, C. Miguel $^{1}$, A. Cardoso $^{2}$, R. Trinca ${ }^{3}$, A. Faustino ${ }^{1}$. ${ }^{1}$ Rheumatology; ${ }^{2}$ Nutrition; ${ }^{3}$ Nurse Day Hospital, Instituto Português de Reumatologia, Lisboa, Portugal

Background: PROs are especially useful in the management of rheumatic diseases in complement to physician evaluation. However they are time consuming and used in a limited manner in the daily clinical practice.

Reuma.pt is the Portuguese national rheumatic diseases register and one of the few registries in Europe that allows the patient to do at home the PROs before the appointment. In our institute we have complemented that with the creation of a paper free day hospital with the use of touch screen computers that also allows the patient to do the PROs before the clinical evaluation by the rheumatologist.

Objectives: to compare the impact of the use off Reuma.pt at home PROs completion platform before and after the utilization of touch screen computers in the day hospital.

Methods: We determined the number of patients and appointments with the use at home of the PROs platform one year prior to the introduction of the touch screen computer at our day hospital (October 2014 -October 2015) and one year after the paper free day hospital was installed (November 2015-November 2016). To determine any change of pattern of the use at home of the platform and the relations between that and patients characteristics.

Results:

Table 1. Diferences between previous use of touchscreen computers in the use at home PROs

\begin{tabular}{lcc}
\hline & $\begin{array}{c}\text { T0 } \\
\text { October 2014 to } \\
\text { October 2015 }\end{array}$ & $\begin{array}{c}\text { T1 } \\
\text { November 2015 to } \\
\text { November de 2016 }\end{array}$ \\
\hline $\begin{array}{c}\text { Number of appointments with PROs done at } \\
\quad \text { home/total of appointments with }\end{array}$ & & \\
$\quad$ completed PROs/percentage & $93 / 419 / 22.1 \%$ & $216 / 448 / 48,2 \%$ \\
Number of patients with PROs done at home & 57 & 106 \\
Age & $45.19 \pm 10.33$ & $49.82 \pm 11.54$ \\
Sex & $40 \mathrm{~F}+17 \mathrm{M}$ & $75 \mathrm{~F}+31 \mathrm{M}$ \\
Mean school years & $11.79 \pm 3.96(\mathrm{~N}=29)$ & $10.35 \pm 4.3(\mathrm{~N}=68)$ \\
Under biologics & 53 appointments (56.99\%) & 162 appointments $(75 \%)$ \\
Diagnosis & 43 AS, 11 RA e 3 PsA & $61 \mathrm{AS}, 33 \mathrm{RA}$ e 12 PsA \\
\hline
\end{tabular}

When we analyse the available variables between the patients that performed the PROs at home we found for both periods considered that they were younger $(45,2 / 49,8$ vs $53,4 / 55,1 p<0.001)$ they have more education $(11.8 / 10.35$ vs $8.2 /$ $7,9)$ no differences were found regarding gender. There is a tendency that with the continuous use of touchscreen computers at the day hospital less educated (T0 -11.8, T1-10.35 school years) and older patients (T0- 45,2/ T1 -49,8 years) are using more at home platform of Reuma.pt.

Conclusions: The use of technology could have a consider impact on the way we collected data from our patients. With the use of a touchscreen computer we have improved not only the overall completion of PROs but also increased the familiarity of patient to the online questionnaires. Number of appoitments with previous at home completion of the questionnaires more than double. This has a clear impact on patient participation, quality of data in the registry but even more impact on time and human resources at a day hospital.

Disclosure of Interest: None declared

DOI: 10.1136/annrheumdis-2017-eular.7001

\section{THU0680 VALIDATION OF EQ-5D, RAPID-3 AND HADS QUESTIONNAIRES FOR THE ASSESSMENT OF THERAPY EFFICACY IN PANNICULITIS PATIENTS}

N. Savushkina, V. Amirdjanova, O. Egorova, B. Belov. V. A. Nasonova Research Institute of Rheumatology, Moscow, Russian Federation

Background: $\mathrm{Pn}$ is a group of heterogeneous inflammatory diseases characterized by involvement of the subcutaneous fat (SF), locomotor system and viscera, and the number of panniculitis $(\mathrm{Pn})$ cases is increasing in everyday practice of a rheumatologists. There are no specific scales available to assess efficacy of Pn therapy. EQ-5D, RAPID-3 and HADS validity, sensitivity and specificity were proven for some rheumatic diseases. Thus, evaluation of EQ-5D, RAPID-3 and HADS psychometric properties in Pn patients has become the objective of this study.

Objectives: Evaluate psychometric properties of questionnaires EQ-5D, RAPID-3 and HADS in Pn patients.

Methods: The study group included $83 \mathrm{Pn}$ pts (80 females, 3males) aged $43,4 \pm 13,9$ years with median disease duration of $5[2 ; 24]$ months who were at the record of V. A. Nasonova Research Institute of Rheumatology during 2009-2015 yy. All patients filled in EQ-5D, RAPID-3 and HADS questionnaires during the first and the control visits at 12 months. Questionnaires' sensitivity was assessed by comparing patient's answers and objective response to therapy measured by achievement of complete regression of the nodules on the control visit. The construct validity was measured based on correlation with "external criteria", including presence of arthritis and arthralgias, tenderness of nodules at palpation measured by VAS, ESR and CRP values.

Results: Positive dynamics (nodule regression) correlated with improved EQ-5D (EQ-5D-scale - $p=0,005$, EQ-5D-VAS - $p=0,004)$ and RAPID-3 $(p=0,0011)$. Median $\triangle \mathrm{EQ}-5 \mathrm{D}$ and HADS-depression after therapy were $0,27[0,12 ; 0,45](p=0,005)$, and $2[1 ; 5](p=0,13)$ scores, respectively, while average decline in RAPID-3 and HADS-anxiety scores after therapy was 9,2 $\pm 5,2(p=0,0011)$ and $4 \pm 3(p=0,15)$, respectively. EQ-5D showed the greatest power in Pn patients' quality of life assessment. EQ-5D-scale and VAS-"thermometer" showed moderate correlation with nodule tenderness at baseline $(r=-0,23, p=0,036) \&(r=-0,45, p=0,0003)$, and control visits (12 months) ( $r=-0,38, p=0,0002)$ \& $(r=-0,41, p=0,0002)$; EQ-5D-scale showed moderate correlation with ESR and CRP values at the control visit $(r=-0,23, p=0,03) \&(r=-0,25, p=0,005)$, and EQ-VAS - with CRP value at 12 months $(r=-0,33, p=0,002)$, demonstrating clear correlation with patient's objective health status and lab parameters values. Moderate correlation between functional RAPID-3 values and nodule tenderness at baseline $(r=0,34$, $p=0,0015)$ and after 12 months $(r=0,5, p<0,0001)$ are also indicative of close links between the questionnaire data and pts' objective health status. As for the HADS scale, moderate correlation was found only between HADS-depression and nodule tenderness at baseline $(r=-0,24, p=0,026)$ and 12 months $(r=0,28$, $p=0,014)$ visits. There were no other significant correlations identified.

Conclusions: EQ-5D and RAPID-3 questionnaires should be considered as valid and sensitive instruments for the assessment of the quality of life and efficacy of therapy in Pn pts.

Disclosure of Interest: None declared

DOI: 10.1136/annrheumdis-2017-eular.2518

\section{THU0681 BASELINE ESSDAI/DAS SCORES IN 8061 PATIENTS WITH PRIMARY SJÖGREN SYNDROME: CHARACTERIZATION OF SYSTEMIC DISEASE}

P. Brito-Zerón ${ }^{1,2}$, N. Acar-Denizli ${ }^{3}$, M. Zeher ${ }^{4}$, A. Rasmussen ${ }^{5}$, X. Li ${ }^{6}$, C. Baldini ${ }^{7}$, J.-E. Gottenberg ${ }^{8}$, D. Danda ${ }^{9}$, L. Quartuccio ${ }^{10}$,

G. Hernandez-Molina ${ }^{11}$, A.A. Kruize ${ }^{12}$, S.-H. Park ${ }^{13}$, M. Kvarnström ${ }^{14}$, S. Praprotnik ${ }^{15}$, D. Sene ${ }^{16}$, A. Alunno ${ }^{17}$, R. Solans ${ }^{18}$, T. Mandl $^{19}$, Y. Suzuki $^{20}$, M. Rischmueller ${ }^{21}$, G. Nordmark ${ }^{22}$, G. Fraile ${ }^{23}$, P. Wiland ${ }^{24}$, H. Bootsma ${ }^{25}$ T. Nakamura ${ }^{26}$, V. Valim ${ }^{27}$, R. Giacomelli ${ }^{28}$, R. Seror ${ }^{29}$

V. Devauchelle-Pensec ${ }^{30}$, B. Hofauer ${ }^{31}$, M. Bombardieri ${ }^{32}$, V. Trevisani ${ }^{33}$, D. Hammenfors ${ }^{34}$, A. Minniti ${ }^{35}$, S.G. Pasoto ${ }^{36}$, J. Morel $^{37}$, S. Retamozo ${ }^{38}$, T.A, Gheita ${ }^{39}$, F. Atzeni ${ }^{40}$, C. Vollenveider ${ }^{41}$, X. Mariette ${ }^{29}$, M. Ramos-Casals ${ }^{2}$ on behalf of EULAR-SS TF Big Data Consortium. ${ }^{1}$ Hosp CIMA-Sanitas; ${ }^{2}$ Hosp Clínic, Barcelona, Spain; ${ }^{3}$ Msgsü, Istanbul, Turkey; ${ }^{4}$ Univ, Debrecen, Hungary; ${ }^{5}$ OMRF, Oklahoma, United States; ${ }^{6}$ Anhui Hosp, Hefei, China; ${ }^{7}$ Univ, Pisa, Italy; ${ }^{8}$ Univ, Strasbourg, France; ${ }^{9} \mathrm{CMC}$, Vellore, India; ${ }^{10}$ Santa Maria, Udine, Italy; ${ }^{11}$ INCMNSZ, México, Mexico: ${ }^{12}$ UMC, Utrecht, Netherlands; ${ }^{13}$ Catholic Univ, Seoul, Korea, Republic Of; ${ }^{14}$ Karolinska Instit, Stockholm, Sweden; ${ }^{15} \mathrm{UMCL}$ Ljubljana, Slovenia; ${ }^{16}$ Lariboisière Hosp, Paris, France; ${ }^{17}$ Univ, Perugia, Italy; ${ }^{18}$ Hosp Vall Hebron, Barcelona, Spain; ${ }^{19}$ Lund Univ, Malmö, Sweden; ${ }^{20}$ Univ, Kanazawa, Japan; ${ }^{21}$ TQEH, Adelaide, Australia; ${ }^{22}$ Univ, Uppsala, Sweden; ${ }^{23}$ Hosp Ramón Cajal, Madrid, Spain; ${ }^{24}$ Med Hosp, Wroclaw, Poland: ${ }^{25}$ Univ, Groningen, Netherlands; ${ }^{26}$ Univ, Nagasaki, Japan; ${ }^{27}$ UFES, Vitória, Brazil; ${ }^{28}$ Univ, L'Aquila, Italy; ${ }^{29}$ Univ Sud, Paris; ${ }^{30}$ Univ, Brest, France; ${ }^{31}$ TUM, München, Germany; ${ }^{32}$ QMUL, London, United Kingdom; ${ }^{33}$ UNIFESP, Sao Paulo, Brazil; ${ }^{34}$ Haukeland Hosp, Bergen, Norway; ${ }^{35}$ Sapienza Univ, Rome, Italy; ${ }^{36}$ USP, Sao Paulo, Brazil; ${ }^{37}$ Univ, Montpellier, France; ${ }^{38}$ INICSA, Cordoba, Argentina; ${ }^{39}$ Univ, Cairo, Egypt; ${ }^{40}$ L.Sacco Univ, Milan, Italy; ${ }^{41}$ German Hosp, Buenos Aires, Argentina

Objectives: To characterize and quantify systemic involvement at diagnosis in a large international cohort of patients with primary Sjögren's syndrome (SS).

Methods: The Big Data Sjögren Project was formed in 2014 to take a "highdefinition" picture of primary SS at diagnosis by merging international databases (9302 consecutive patients from 21 countries of the 5 continents). The main features (including ESSDAI/DAS) at diagnosis were analysed.

Results: Baseline ESSDAI was available in 8061 patients $(93 \%$ female, mean age $53 \mathrm{yrs}$ ). The mean ESSDAI score at diagnosis of the entire cohort was $6.4 \pm 7.9$. In 1498 patients (19\%), score at diagnosis was 0, while $681(8 \%)$ presented with high activity in at least one domain. The main systemic features at diagnosis were 